reduced hypoxia and a decrease in regulatory $\mathrm{T}$ cells. However, bevacizumab exposure increased the influx of PDGFCexpressing macrophages capable to bypass VEGFA-dependent angiogenesis.

\section{THE PROGNOSTIC VALUE OF THE PERITONEAL CANCER INDEX (PCI) AFTER SUGARBAKER FOR THE EFFECT OF NEOADJUVANT CHEMOTHERAPY IN ADVANCED OVARIAN CANCER}

F Rawert*, V Luengas-Würzinger, S Claßen von Spee, S Baransi, E Schuler, K Carrizo, P Mallmann, B Lampe.

\subsection{6/ijgc-2021-ESG0.402}

Introduction/Background* Advanced epithelial ovarian cancer (EOC) is a severe disease with high mortality rate. Achieving complete cytoreduction $(\mathrm{R}=0 ; \mathrm{CCR})$ is crucial for the patient's prognosis. Extensive peritoneal carcinomatosis is often the limiting factor for achieving CCR in EOC and therefore is the deciding factor for therapy planning. The Peritoneal Cancer Index (PCI) after Sugarbaker has been an established tool to describe the extension of the disease. A patient presenting a PCI $<25$ is considered to be operable ${ }^{1}$. We examined the predictive power of various markers (CA-125, CTscans, PCI) for achieving complete cytoreduction after neoadjuvant chemotherapy (NACT).

Methodology The data of 23 patients treated in our hospital between 01/2015 und 12/2020 with inoperable EOC were retrospectively analyzed. Clinical and radiological data were collected and statistically analysed (univariate analysis: Chi-Square Tests, Mann-Whitney $U$ test and multivariate analysis: Binary logistic regression, ROC-curve).

Result(s)* The reduction of the PCI itself after neoadjuvant chemotherapy showed to be a powerful predictor for complete cytoreduction (CCR), but it also showed to be significant even if the different PCI baseline values were considered. The reduction of the initial PCI score by minimum 8.5 points was a better predictor for CCR than the PCI $<25$.

Neither the RECIST analysis ${ }^{2}$ of the CT-scans nor the reduction of the tumor marker CA-125 proved to be a significant predictor.

Conclusion* Whether CCR can be achieved during debulking surgery, is best predicted by the reduction of the PCI. A combination of the three markers might be even more powerful. Larger studies are needed to confirm this.

\section{PATIENT CHARACTERISTICS AND TREATMENT PATTERNS BY BRCA/ATM MUTATION STATUS IN OVARIAN CANCER PATIENTS: AN EHR ANALYSIS IN THE PRIOR-2 STUDY}

${ }^{1} \mathrm{G}$ Adeboyeje*, ${ }^{2} \mathrm{M}$ Sierra, ${ }^{2} \mathrm{~A}$ Bartels, ${ }^{2} \mathrm{M}$ Field, ${ }^{3} \mathrm{~S}$ Jhamb, ${ }^{3} \mathrm{~A}$ Buikema, ${ }^{4} \mathrm{~S}$ Joo. ${ }^{1}$ Merck and Co., Inc., MRL, Center for Observational and Real-World Evidence (CORE), Oncology, Kenilworth, USA; ${ }^{2}$ Optum, Commercial Analytics, Eden Prairie, USA; ${ }^{3}$ Optum, Health Economics and Outcomes Research, Eden Prairie, USA; ${ }^{4}$ Merck and Co., Inc., MRL, Center for Observational and Real-World Evidence (CORE), Oncology, North Wales, USA

\subsection{6/ijgc-2021-ESG0.403}

Introduction/Background* Previous studies have reported median progression-free survival (PFS) of 12-18 months in ovarian cancer (OC). Testing for BRCA1/2 or ATM gene
Abstract 451 Table 1 Treatments received and transition rates through lines of therapy or death

\begin{tabular}{|c|c|c|c|c|c|c|}
\hline \multirow{2}{*}{$\begin{array}{l}\text { Landmark } \\
\text { BRCA/ATM Mutational Status }\end{array}$} & \multicolumn{2}{|c|}{6 Months } & \multicolumn{2}{|c|}{12 Months } & \multicolumn{2}{|c|}{24 Months } \\
\hline & Yes & No & Yes & No & Yes & No \\
\hline Number Treated & 203 & 221 & 237 & 253 & 264 & 282 \\
\hline $\begin{array}{l}\text { Received PARP Inhibitor (any } \\
\text { line), } \%\end{array}$ & 25.6 & 6.3 & 43.5 & 17.4 & 51.5 & 24.5 \\
\hline $\begin{array}{l}\text { Received Bevacizumab (any } \\
\text { line),\% }\end{array}$ & 14.8 & 17.2 & 21.1 & 29.6 & 25.4 & 34.4 \\
\hline $\begin{array}{l}\text { Transitions through lines of } \\
\text { therapy, } \%\end{array}$ & & & & & & \\
\hline $\begin{array}{l}\text { receiving/completed } 2 \mathrm{~L} \\
\text { treatment or died }\end{array}$ & 31.5 & 21.3 & 54.4 & 46.6 & 63.6 & 63.5 \\
\hline $\begin{array}{l}\text { receiving/completed } 3 \mathrm{~L} \\
\text { treatment or died }\end{array}$ & 4.9 & 5.0 & 23.2 & 15.0 & 39.8 & 32.6 \\
\hline
\end{tabular}

mutations in OC can inform treatment choice. Data on the treatment experience of patients with OC by BRCA/ATM mutational status in the United States (US) is needed.

Methodology We identified female adults, $\geq 18$ years, with OC from Optum's de-identified electronic health record (EHR) database $(1 / 1 / 2017$ - 6/30/2020; $\mathrm{N}=16.6 \mathrm{M}$ female lives). Index date was first diagnosis of OC. Patients were observed for 12-months pre-index to capture baseline demographic, clinical and prognostic characteristics. Treatment with platinum-taxane CT, PARPi, bevacizumab and transition rates through lines of therapy or death by BRCA/ATM mutational status was examined.

Result(s)* Among 1,901 OC patients tested for BRCA/ATM gene mutation, $616(32.4 \%)$ were positive, 682 (35.9\%) were negative and 603 (31.7\%) had unknown status. Mean (SD) age was 59.5 (10.9) and 62.2 (12.1) years for patients with BRCA/ATM mutation and no mutation. No meaningful differences by BRCA/ATM mutational status (yes vs no) were found in the proportion of patients with stage $3 / 4$ cancer $(52.1 \%$ vs $52.1 \%)$, visceral metastasis $(35.9 \%$ vs $31.8 \%)$ or ascites $(30.8 \%$ vs $30.2 \%)$, at presentation; or in $1 \mathrm{~L}$ platinum-taxane CT initiation $(55 \%$ at 6 months). PARPi use differed by BRCA/ATM status and increased over time (table 1).

Conclusion* While there are few differences in characteristics between patients by BRCA/ATM status, PARPi use was higher in patients with BRCA/ATM mutation; patients with no BRCA/ATM mutation were more often treated with bevacizumab. There is need for further research to understand the role of BRCA/ATM status on treatment choice and outcomes.

\section{GENETIC PROFILE BY WHOLE EXAM SEQUENCING OF A PATIENT'S BORDERLINE TUMOR AND ITS RELAPSE: A CASE REPORT}

${ }^{1} \mathrm{D}$ Atallah*, ${ }^{2} \mathrm{El}$ Feghaly, ${ }^{3} \mathrm{E}$ Choueiry, ${ }^{4} \mathrm{~N}$ Jalkh, ${ }^{3} \mathrm{C}$ Mehawej, ${ }^{5} \mathrm{H}$ Kourie, ${ }^{6} \mathrm{~A}$ Khaddage, ${ }^{7} \mathrm{M}$ Akiki, ${ }^{1} \mathrm{~N}$ El Kassis, ${ }^{5} \mathrm{G}$ Chahine, ${ }^{8} \mathrm{M}$ Moubarak. ${ }^{1}$ Hôtel-Dieu de France University Hospital, Obstetrics and Gynecology , Beirut, Lebanon; ${ }^{2}$ Hôtel-Dieu de France University Hospital, Beirut, Lebanon; ${ }^{3}$ Lebanese American University, Human Genetics, Beirut, Lebanon; ${ }^{4}$ Saint Joseph University, Unité de Génétique Médicale, Lebanon; ${ }^{5}$ Hôtel-Dieu de France University Hospital, Saint Joseph University, Oncology, Beirut, Lebanon; ${ }^{6}$ Hôtel-Dieu de France University Hospital, Saint Joseph University, Pathology, Beirut, Lebanon; 'HôtelDieu de France University Hospital, Pathology, Beirut, Lebanon; ${ }^{8}$ Hôtel-Dieu de France University Hospital, Saint Joseph University, Obstetrics and Gynecology, Beirut, Lebanon

10.1136/ijgc-2021-ESGO.404 